\section{Archives of Allergy \\ and Immunology}

Int Arch Allergy Immunol 2021;182:819-826

DOI: $10.1159 / 000514973$
Received: December 15, 2020

Accepted: January 22, 2021

Published online: April 22, 2021

\title{
Prophylactic Treatment in Hereditary Angioedema Is Associated with Reduced Anxiety in Patients in Leipzig, Germany
}

\author{
Julia Zarnowski Marie Rabe Paula Kage Jan-Christoph Simon \\ Regina Treudler \\ Department of Dermatology, Venereology and Allergology, University Hospital Leipzig, Leipzig, Germany
}

\section{Keywords}

Hereditary angioedema · Burden of disease - Quality of life · Anxiety · Depression · Long-term prophylaxis · Angioedema control test

\begin{abstract}
Background: Hereditary angioedema (HAE) is associated with relevant disease-related burden. We aimed at investigating prevalence of depression and anxiety in patients with HAE in Leipzig, Germany. Methods: Questionnaire-based evaluation of medical history, Angioedema Control Test (AECT), Angioedema Quality of Life Questionnaire (AE-QoL), Generalized Anxiety Disorder Scale-7 (GAD-7), and Hospital Anxiety and Depression Scale (HADS). Results: Thirty-seven patients with HAE were included (31 females, mean age $49.6 \pm 17.5$ years). A mean diagnostic delay between first symptoms and correct diagnosis of $14.2 \pm 14.5$ years was detected. Patients aged $<50$ years $(n=18)$ had been diagnosed significantly earlier with HAE than older patients $(p=<0.001)$. In 6 patients $(16.2 \%)$, unnecessary medical interventions were performed and 14 patients (43.8\%) reported at least 1 HAE-related death of a family member. Psychological stress was the most common triggering factor (96.2\%). HADS scores revealed depression in 5/37 patients (13.5\%) and anxiety in 16/37 (43.2\%), GAD-7 score indicated anxiety in 9/36
\end{abstract}

(25\%) participants. Patients receiving long-term prophylactic treatment $(n=17,45.9 \%)$ showed significantly better disease control (AECT; $p=<0.001$ ) and quality of life (AE-QoL; $p=<0.001)$ compared to those with on-demand treatment only. Patients with long-term prophylactic treatment showed significantly lower scores for anxiety and depression at GAD-7 ( $p=0.011$ ) and HADS (anxiety: $p=0.021$; depression: $p=0.008$ ). In 5 patients, treatment regime was changed as AECT score indicated insufficient disease control. Subsequently, we measured significant improvement of quality of life (AE-QoL, $p=0.04$ ) and disease control (AECT; $p=0.032$ ). Conclusion: Anxiety was a frequent burden in our study group and showed a significant association with low disease control. Our data indicate that prophylactic HAE treatment can improve psychosocial burden of HAE.

(C) 2021 The Author(s)

Published by S. Karger AG, Basel

\section{Introduction}

Hereditary angioedema (HAE) is characterized by unpredictable mucocutaneous swellings, which are often accompanied by external disfigurement, severe pain, or in-

Edited by: H.-U. Simon, Bern.
(C) 2021 The Author(s)

Published by S. Karger AG, Basel

This is an Open Access article licensed under the Creative Commons Attribution-NonCommercial-4.0 International License (CC BY-NC) (http://www.karger.com/Services/OpenAccessLicense), applicable to the online version of the article only. Usage and distribution for commercial purposes requires written permission.
Correspondence to:

Julia Zarnowski, julia.zarnowski@medizin.uni-leipzig.de 
creased risk of asphyxia [1-3]. The autosomal dominant disorder usually becomes symptomatic in the first decade of life and often involves multiple family members. Lifelong persisting symptoms may lead to relevant absences from school or work, which can result in educational or career impairments and significantly increase the absenteeism of caregivers [4].

There are reports on considerable disease-related burden in children and adult patients with HAE [5-8]. Up to $15-46 \%$ of patients report clinically significant anxiety symptoms and $18-42 \%$ of patients show relevant depressive symptoms [9-13]. Psychiatric comorbidities are also seen in pediatric HAE patients, with up to $24.5 \%$ showing depression or anxiety and up to $44.8 \%$ receiving antidepressants or anxiety-related medication [12].

Several relevant factors, such as a history of severe HAE attacks, HAE-related deaths within the family, unpredictability of attacks, impairment of family planning decisions, delay of correct diagnosis, unnecessary medical interventions due to misdiagnosis and disease-related restrictions of daily activities or work productivity are contributing to the huge burden of the disease in HAE patients $[3,10,14-20]$. We aimed at analyzing diseaserelated burden in adult patients with HAE in Leipzig, Germany.

\section{Material and Methods}

\section{Study Design and Patients}

Monocentric, questionnaire-based study that included adult patients with HAE who presented in our $\mathrm{GA}^{2} \mathrm{LEN}$ certified Angioedema Center of Reference and Excellence (ACARE) at the department of dermatology, venereology, and allergology (University of Leipzig, Leipzig, Germany) [21].

\section{Questionnaires}

We used in-house questionnaires to assess patient's medical history and validated questionnaires for disease activity and psychosocial outcome parameters. The Angioedema Control Test (AECT) is a validated, retrospective instrument, which aims to evaluate disease control in patients with recurrent angioedema over a recall period of 4 weeks. The AECT consists of 4 questions, which can be scored from 0 (strongly impaired/no control) to 4 (no impairment/good control) each, reaching a total score of $0-16$. A cutoff value of $<10$ points corresponds to poorly controlled disease [22, 23].

The Angioedema Quality of Life Questionnaire (AE-QoL) is used to assess impairments on 4 dimensions of quality of life (food, functioning, mood, and fear/shame) over a period of 4 weeks. The questionnaire consists of 17 questions scoring from 1 (no impairment) to 5 (strong impairment). The total sum is converted to a linear $0-100$ scale with 0 indicating no impairment and 100 a maximum impairment of quality of life [24].
The Hospital Anxiety and Depression Scale (HADS) includes 14 items, of which 7 questions relate to anxiety symptoms and depressive symptoms, respectively. Each item is scored from 0 (no impairment) to 3 (pronounced feelings of, e.g., joylessness or fear). The sum for anxiety and depression is calculated individually and can reach a total score from 0 to 21 . A sum score up to 7 is unsuspicious; a score between 8 and 10 indicates moderate anxiety or depression and values $\geq 11$ relate to a pronounced degree of anxiety or depression. The recall period is 1 week [25].

We also used a German version of the established questionnaire Generalized Anxiety Disorder-7 (GAD-7) to screen for anxiety. The GAD-7 (covering symptoms of generalized anxiety disorder, panic disorder, social anxiety disorder, and post-traumatic stress disorder) consists of 7 items, which refer to the frequency of encountered symptoms during the last 4 weeks. The score reaches from 0 to 3 points for each item ( 0 : not at all, 1 : several days, 2: more than half the days, and 3: nearly every day) with a maximum score of 21 . A total sum of $\geq 10$ indicates moderate anxiety symptoms and a cutoff point $\geq 15$ is indicative of severe anxiety symptoms [26].

\section{Statistical Analysis}

Statistical analysis was performed with IBM SPSS Statistics, Version 24.0. Descriptive results were presented as absolute numbers, percentages, means, medians, as well as standard deviations, and interquartile ranges when appropriate. A $p$ value of $<0.05$ was considered to be statistically significant. For further analysis, patients were divided into 2 groups, either depending on their age (agegroup 1: $<50$ years; age-group 2: $\geq 50$ years) or concerning their treatment modality (treatment group 1: on-demand treatment only and treatment group 2: long-term prophylaxis). Mann-Whitney $U$ test was used to evaluate group differences and Spearman's rank correlation coefficient $\left(r_{\mathrm{s}}\right)$ to measure the strength of associations.

\section{Results}

\section{Patient Characteristics and Course of Disease}

We included 37 patients with $\mathrm{HAE}$, of which 31 $(83.8 \%)$ were female and $6(16.2 \%)$ male. Thirty patients (81\%) were diagnosed with HAE type I, 3 patients $(8.1 \%)$ with type II, and 4 individuals (10.8\%) had HAE with normal C1 inhibitor (HAEwnC1INH). Mean age was $49.6 \pm$ 17.5 years, with 18 subjects ( $48.6 \%)$ aged below 50 years (age-group 1). The mean age at onset of symptoms was $14.6 \pm 7.7$ years, and the mean age at diagnosis was 28.7 \pm 16.1 years. Younger patients (age-group 1) were diagnosed significantly earlier in life than older patients $(20.6$ \pm 10.8 vs. $36.4 \pm 16.8$ years; $p=0.002$ ), and they had a significantly shorter delay between first symptoms and received HAE diagnosis ( $8.4 \pm 7.1$ vs. $19.6 \pm 17.5$ years; $p=$ $<0.001)$. There was a significant correlation between older patient's age and delay of diagnosis (correlation coefficient $r_{\mathrm{s}}=0.547 ; p=<0.001$ ).

Six patients reported medical interventions due to misdiagnosed HAE attacks with appendectomy in 4 pa- 
Table 1. Disease control, quality of life and mental health in relation to treatment modality

\begin{tabular}{|c|c|c|c|c|c|}
\hline $\begin{array}{l}\text { Questionnaire and treatment } \\
\text { modality }\end{array}$ & $n$ & $\%$ & Mean \pm SD & Median [IQR] & $\begin{array}{l}\text { Significance } \\
p \text { value }\end{array}$ \\
\hline AECT & 37 & 100 & $10.2 \pm 4.8$ & $12.0[5.5-15.0]$ & \multirow{3}{*}{$<0.001$} \\
\hline On-demand only & 20 & 54.1 & $7.6 \pm 4.6$ & $7.0[4.0-12.0]$ & \\
\hline Prophylaxis & 17 & 45.9 & $13.2 \pm 2.8$ & $13[12.0-15.0]$ & \\
\hline AE-QoL & 37 & 100 & $31.5 \pm 14.3$ & $30.6[21.2-41.2]$ & \multirow{3}{*}{$<0.001$} \\
\hline On-demand only & 20 & 54.1 & $36.7 \pm 14.9$ & $34.7[27.4-50.0]$ & \\
\hline Prophylaxis & 17 & 45.9 & $24.0 \pm 9.6$ & $23.5[18.8-31.5]$ & \\
\hline GAD-7 & 36 & 97.3 & $6.0 \pm 5.2$ & $4.0[2.25-9.0]$ & \multirow{4}{*}{0.011} \\
\hline On-demand only & 20 & 55.6 & $8.2 \pm 5.9$ & $8.5[3.0-12.25]$ & \\
\hline Prophylaxis & 16 & 44.4 & $3.3 \pm 2.5$ & $4.0[0.25-4.75]$ & \\
\hline HADS & 37 & 100 & $10.6 \pm 7.6$ & $8.0[5.0-16.0]$ & \\
\hline On-demand only & 20 & 54.1 & $13.5 \pm 7.6$ & $14.0[5.75-17.75]$ & \multirow{2}{*}{0.012} \\
\hline Prophylaxis & 17 & 45.9 & $7.2 \pm 6.4$ & $5.0[2.0-10.5]$ & \\
\hline HADS-A & 37 & 100 & $6.5 \pm 4.5$ & $7.0[3.0-10.0]$ & \multirow{3}{*}{0.021} \\
\hline On-demand only & 20 & 54.1 & $8.1 \pm 4.5$ & $8.5[4.0-10.75]$ & \\
\hline Prophylaxis & 17 & 45.9 & $4.7 \pm 3.9$ & $4.0[2.0-7.0]$ & \\
\hline HADS-D & 37 & 100 & $4.1 \pm 3.7$ & $3.0[1.0-6.5]$ & \multirow{3}{*}{0.008} \\
\hline On-demand only & 20 & 54.1 & $5.4 \pm 3.8$ & $5.0[3.0-7.0]$ & \\
\hline Prophylaxis & 17 & 45.9 & $2.5 \pm 3.1$ & $1.0[0.0-4.0]$ & \\
\hline
\end{tabular}

Scores of questionnaires used (AECT, Angioedema Control Test; AE-QoL, Angioedema Quality of Life Questionnaire; GAD-7, Generalized Anxiety Disorder-7; HADS, Hospital Anxiety and Depression Scale (A, Anxiety; $\mathrm{D}$, Depression); SD, standard deviation; IQR, interquartile range).

tients as well as 1 gynecological intervention, 1 gastroscopy, 1 laparoscopy, and 1 ascites puncture. In some patients, multiple interventions had been performed. Subjects with unnecessary medical interventions showed an increased average age of $58.3 \pm 12.2$ years with 5 of 6 patients belonging to age-group 2 ( $\geq 50$ years) and only 1 patient being younger than 50 years (age-group 1).

Family history was positive in $32 / 37$ (86.5\%) patients with a mean number of 3.3 (range 1-6) affected family members. HAE-associated deaths of family members were reported in $14 / 32$ patients ( $43.8 \%$ of all with positive family history). The loss of a family member due to HAE has not been significantly different in both age-groups (6 patients from age-group 1 and 8 patients from age-group $2, p=0.663)$. A total of $26 / 37(70.3 \%)$ patients reported HAE attacks within the last 12 months with cutaneous swellings in all symptomatic patients $26 / 26$ (100\%), abdominal symptoms in $22 / 26$ (84.6\%), depressive symptoms in $7 / 26(26.9 \%)$, and laryngeal swellings in $6 / 26$ (23.1\%) patients. Trigger factors reported were psychological stress in 25/26 (96.2\%) patients, mechanical pressure in $13 / 26(50 \%)$, hormonal factors in $12 / 26(46.2 \%)$, infections in $8 / 26(30.8 \%)$, medication in $5 / 26(19.2 \%)$, excessive emotions in $4 / 26$ (15.4\%), surgery/medical in- tervention or insect bite in $2(7.7 \%)$, respectively, and physical exercise, vaccination, or temperature changes in 1 patient (3.8\%), respectively.

The great majority of patients $(n=34,91.9 \%)$ received on-demand treatment, either additionally $(n=14,37.8 \%)$ or solely (treatment group $1, n=20,54.1 \%$ ) with Icatibant being most commonly used. Seventeen patients (treatment group 2, 45.9\%) had long-term prophylactic treatment, mainly with $\mathrm{C} 1 \mathrm{INH}$ concentrate; 3 were treated with Danazol and 2 with Lanadelumab. Five patients were switched to long-term prophylactic treatment due to insufficient symptom control. Patients reported $14.7 \pm 28.6$ disease-related absence days on average due to HAE attacks with a minimum of 0 and a maximum of 100 days in the last 12 months.

\section{Depression and Anxiety}

The GAD-7 questionnaire was completed by $36 / 37$ patients. Nine patients $(25 \%)$ had scores $\geq 10$, indicating considerable anxiety symptoms. The HADS scores indicated anxiety in $16(43.2 \%)$ patients and depression in 5 (13.5\%) patients. Subjects, who received long-term prophylaxis, showed significantly lower values of GAD-7 $(p=0.011)$, HADS total $(p=0.012)$, HADS anxiety $(p=$ 


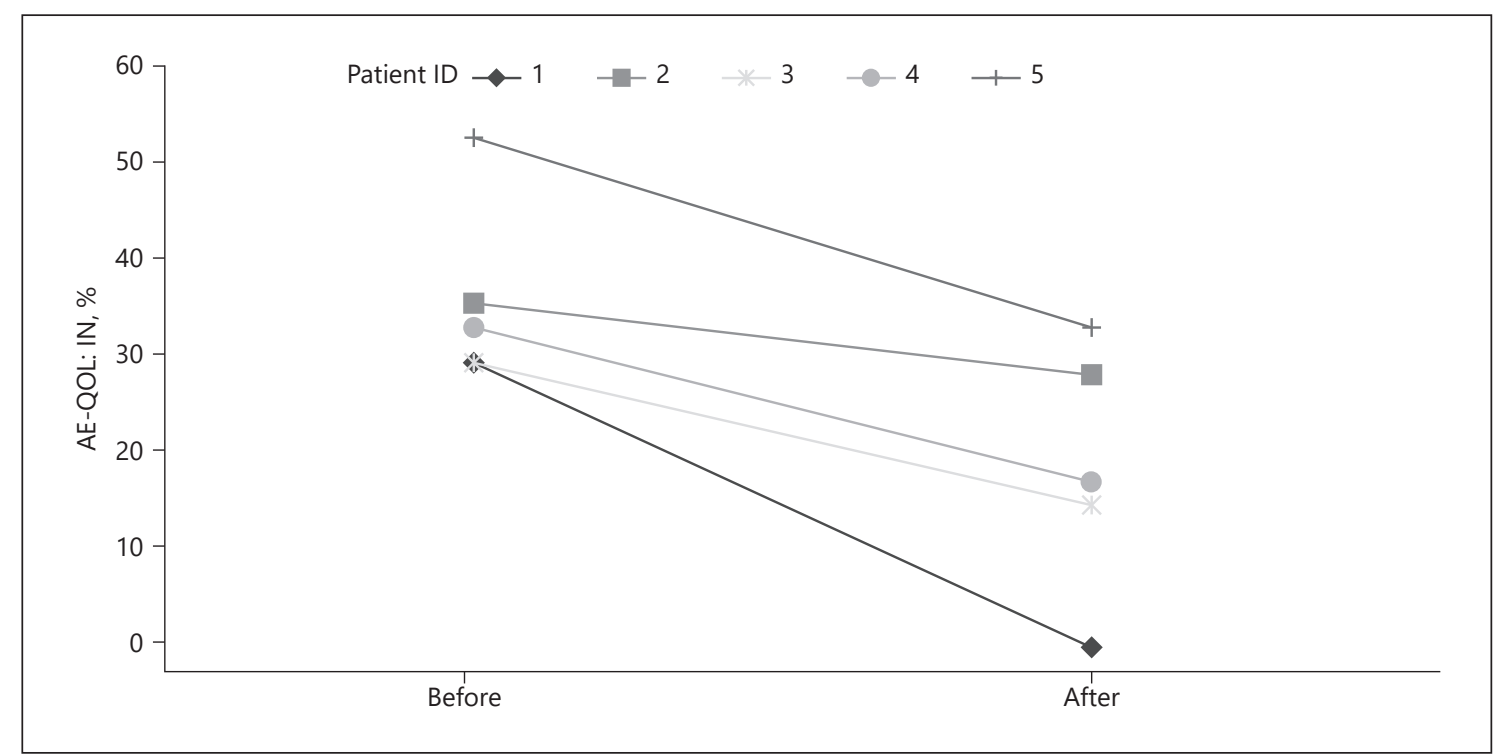

Fig. 1. Change in AE-QoL before and after switch of treatment in 5 patients. Median values decreased from 34.1 to $18.8(p=0.04)$, indicating a significantly reduced impairment of quality of life.

$0.021)$, and HADS depression $(p=0.008)$ than those who were on-demand treatment only (Table 1$)$.

\section{Disease Control and Quality of Life}

Mean AECT score was $10.2 \pm 4.8$ indicating well-controlled symptoms on average, and however, 15/37 patients $(40.5 \%)$ reached AECT scores $<10$, indicating insufficient symptom control (Table 1). Subjects on longterm prophylactic treatment showed significantly higher AECT values $(p=<0.001)$. AE-QoL showed significantly lower values, indicating better quality of life in patients on long-term prophylactic treatment $(p=<0.001)$.

\section{Correlation between Control of Disease, Quality of}

Life, and Mental Symptoms

There was a significantly negative correlation between AECT values and HADS total $\left(r_{s}=-0.469, p=0.003\right)$, HADS anxiety $\left(r_{\mathrm{s}}=-0.386, p=0.018\right)$, HADS depression $\left(r_{\mathrm{s}}=-0.494, p=0.002\right)$, GAD-7 $\left(r_{\mathrm{s}}=-0.614, p=<0.001\right)$, and disease-related absences $\left(r_{\mathrm{s}}=-0.369, p=0.025\right)$. There was a significantly positive correlation between AE-QoL and HADS total $\left(r_{s}=0.613, p=<0.001\right)$, HADS$\mathrm{D}\left(r_{\mathrm{s}}=0.556, p=<0.001\right)$, HADS-A $\left(r_{\mathrm{s}}=0.574, p=\right.$ $<0.001)$, and GAD-7 $\left(r_{s}=0.668 ; p=<0.001\right)$. A significantly negative correlation between AECT and AE-QoL $\left(r_{s}=-0.691, p=<0.001\right)$ indicates that a better therapeutic control is strongly associated with a lower impairment of quality of life.
Subgroup Analysis after Switch of Treatment Regimes

In patients with persistently low AECT values, we offered to switch treatment regime. Five of those patients (all with HAE type 1; 4 female; mean age 59.0 years) agreed to participate in a follow-up survey. Previous treatment included Icatibant $(n=3)$ or recombinant C1INH $(n=2)$. Three patients were switched to longterm treatment with recombinant C1INH; 2 others were switched from recombinant C1INH to Lanadelumab. They were on this new therapy for a mean of $9.2 \pm 8.4$ months at the time of follow-up. Our analysis revealed a statistically significant improvement of quality of life (AE-Qol mean change: $36.9 \pm 9.3$ vs. $20.2 \pm 12.4$; median change: 34.1 [30.6-44.7] vs. 18.8 [9.4-31.8]; $p=0.04$; Fig. 1). Additionally, a significant improvement of therapeutic control was seen (AECT mean change: $4.4 \pm 5.5 \mathrm{vs}$. $12.6 \pm 4.5$; median change: 5.0 [1.0-7.5] vs. 15.0 [8.5$15.5] ; p=0.032$; Fig. 2). HADS and GAD-7 scores slightly improved but did not show any significant differences.

\section{Discussion}

In this study, we investigated the burden of disease in a group of 37 adult patients with HAE treated in our ACARE center in Leipzig, Germany. To our knowledge, this is the first study to correlate the patient-reported disease control with psychosocial scores and treatment regime. 


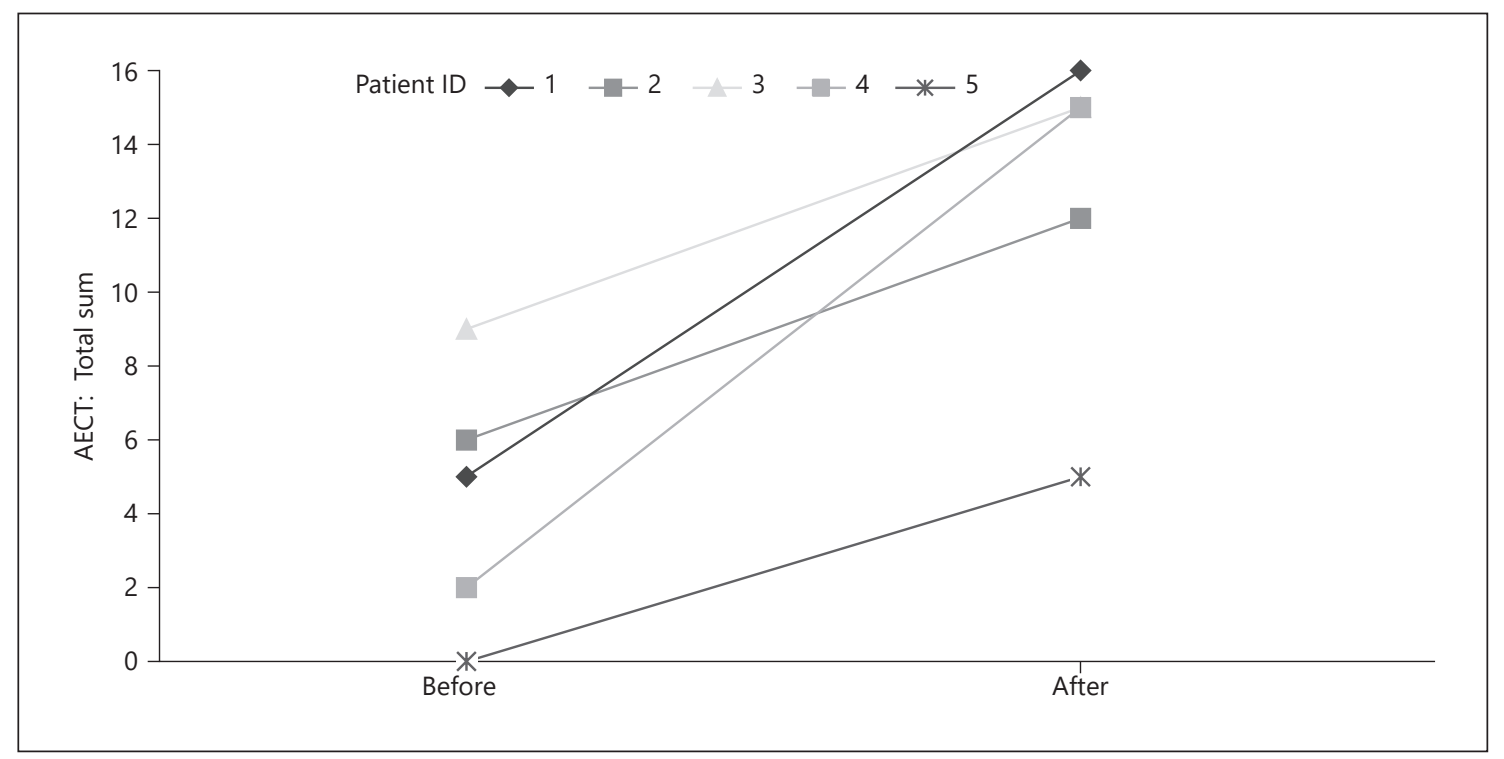

Fig. 2. Change in AECT before and after switch of treatment in 5 patients. Median values increased from 5.0 to $15.0(p=0.032)$, indicating improved disease control.

Our results show a long diagnostic delay, misdiagnoses, and family burden due to HAE, which is consistent with previously published data. Other study groups reported an average diagnostic delay of 8.5 years with up to $65 \%$ of patients receiving at least 1 misdiagnosis and $24 \%$ reporting dispensable medical interventions while averagely consulting 4.4 physicians until HAE was correctly diagnosed [2729]. A study by Magerl et al. [30] shows that up to $80 \%$ of misdiagnosed HAE patients also receive a pharmaceutical or interventional mistreatment. Comparable to our findings, other study groups have described a significantly longer diagnostic delay in elder patients [30,31]. Data from the Icatibant Outcome survey show an average diagnostic delay of 23.9 years in the $>65$-year-old age-group compared to 4.8 years in the $<65$-year-old group [31]. Recent data from Germany show an average diagnostic delay of 18.1 years, which increases to 22.9 years in 60-79-year-old patients and to 38.5 years in the $\geq 80$-year-old group [30].

The potentially fatal course of HAE significantly increases disease-related burden, enhancing fear and anxiety of patients due to their individual health, while also increasing concern for affected family members. In a German study from 2012, HAE-related deaths from 182 families were evaluated, identifying 70 deaths due to a fatal laryngeal swelling. $90 \%$ of deceased patients have not received their HAE diagnosis before death and had a significantly reduced lifespan with an average age of 40.6 years at asphyxiation [32].

Prophylactic Treatment Reduces Anxiety in Hereditary Angioedema
Altogether, the delay of diagnosis, misdiagnosis, mistreatment, and family burden results in a tremendous impairment of quality of life and can promote psychiatric comorbidities. However, a reduced misdiagnosis and mistreatment in younger patients is suggesting an improvement of diagnostic measures over the last decades.

With regard to psychiatric comorbidities, our data show a substantial prevalence of depression and anxiety, which is comparable to previously published studies [9$11,13]$. In spite of modern therapeutic options, high rates of anxiety and depression in HAE patients remain a serious comorbidity. Only recently, anxiety and depression were reported to occur in 35.3 and $20.9 \%$ of $445 \mathrm{HAE}$ patients from the USA, respectively [20]. In our study, a significantly better control of disease, markedly better quality of life and lower depression and anxiety rates were seen in patients who received long-term prophylactic medication, compared to those who are treated with ondemand treatment only. These results are in accordance with recent data, showing that a better control of HAE attacks goes along with lower anxiety and depression symptoms as well as with improved quality of life outcomes [33-38].

However, our subgroup analysis could not detect a significant improvement of anxiety and depression scores when patients were switched on long-term prophylactic treatment. It remains unclear, whether the duration of long-term treatment is essential to improve or 
maintain mental health, as our patients were taking their prophylactic medication for $<1$ year. It should be also discussed, whether the lifelong persisting burden of disease, unpredictable breakthrough attacks in spite of prophylactic treatment or even common neurobiological processes are critical features, altogether leading to a substantial prevalence of mental diseases in HAE patients [ 9 , 13, 39-41].

Neuroimmunological animal studies suggest that kinin-receptors can influence depressive behavior in mice [42]. To investigate the role of kinin-receptors, mice with depressive behavior were administered with B1-kinin receptor antagonists, which led to a significant inhibition of depressive behavior. Generally, B1-kinin-receptors are increasingly expressed under pathological conditions such as stress, chronic pain, and inflammation. It can be discussed whether lifelong recurrent $\mathrm{HAE}$, accompanied by psychosocial stress, fear, and physical pain might induce an upregulation of the B1-receptors and, thus, have a neuroimmunological influence on depressive behavior patterns [42].

In a recently published study by Savarese et al. [43], nearly half of the investigated patients (48\%) showed psychopathological discomfort and clinically relevant psychological vulnerability. Also, a lower ability of engagement with their disease was seen in almost one-third (28.6\%) of HAE patients, which significantly correlated with the presence of stress. Although reduced emotional regulation enforces the inability to manage one's health, a better knowledge of disease has a positive impact on a patient's health engagement, possibly reducing clinically relevant stress. As psychological stress is described as most common trigger factor for HAE attacks, which was also seen in our study group, the authors suggest that psychological and experiential processes of HAE patients might offer a possible therapeutic target for clinical psychologists [41, 43, 44].

With novel prophylactic treatment options for HAE, disease control and associated mental comorbidities are expected to improve. However, due to high costs, the availability of modern drugs will be likely limited to a selected group of patients worldwide [19, 45-48].

In conclusion, anxiety was a frequent burden in our study group and was significantly associated with low disease control as measured by AECT. Our data indicate that therapeutic interventions aiming at minimizing number and severity of HAE attacks can significantly improve quality of life and control of disease in HAE patients. It also emphasizes that psychometric tests are valuable tools to measure quality of life, mental health issues, and therapeutic success and should be integrated routinely into the treatment of HAE patients [49].

\section{Statement of Ethics}

This study complies with the guidelines for human studies and was conducted ethically in accordance with the World Medical Association Declaration of Helsinki. This study received approval from the ethical board of the Medical Faculty of the University of Leipzig (Vote Nr.: 115/19-ek). A written consent was obtained from all participants.

\section{Conflict of Interest Statement}

All the authors were involved in clinical studies on diagnosis and therapy of HAE, funded by TAKEDA, CSL Behring, and Centogene. R.T. received lecture fees, and J.L., M.R., and R.T. received travel grants from TAKEDA and CSL Behring.

\section{Funding Sources}

The authors did not receive any funding.

\section{Author Contributions}

J.Z. and R.T. made the concept of the study. All the authors were involved in acquisition, analysis, and interpretation of data and paper writing. All the authors gave their final, and prepublished approval of the version and agree to be accountable for all aspects of the work.

\section{References}

1 Magerl M, Brasch J, Förster U, Hauswald B, Mohr B, Präßler J, et al. Diagnostik und Ausschluss des hereditären Angioödems. Hautarzt. 2012;63(7):567-72.

2 Maurer M, Magerl M, Ansotegui I, AygörenPürsün E, Betschel S, Bork K, et al. The international WAO/EAACI guideline for the management of hereditary angioedema: the 2017 revision and update. World Allergy Organ J. 2018;11(1):1-20.
3 Bova M, De Feo G, Parente R, De Pasquale T, Gravante C, Pucci S, et al. Hereditary and acquired angioedema: heterogeneity of pathogenesis and clinical phenotypes. Int Arch Allergy Immunol. 2018;175(3):126-35.

4 Nygren A, Nordenfelt P, Lindfors A, Mallbris L, Björkander J, Wahlgren CF. Swedish children with hereditary angioedema report good overall health and quality of life despite symptoms. Acta Paediatr. 2016;105(5):529-34. 
5 Busse PJ, Christiansen SC, Birmingham JM, Overbey JR, Banerji A, Otani IM, et al. Development of a health-related quality of life instrument for patients with hereditary angioedema living in the United States. J Allergy Clin Immunol Pract. 2019;7(5):167983.e7.

6 Liu S, Wang X, Xu Y, Xu Q, Zhi Y. Healthrelated quality of life and its risk factors in Chinese hereditary angioedema patients. Orphanet J Rare Dis. 2019;14(1):1-8.

7 Jindal NL, Harniman E, Prior N, Perez-Fernandez E, Caballero T, Betschel S. Hereditary angioedema: health-related quality of life in Canadian patients as measured by the SF-36. Allergy Asthma Clin Immunol. 2017; 13(1):4.

8 Aygören-Pürsün E, Bygum A, Beusterien K, Hautamaki E, Sisic Z, Boysen HB, et al. Estimation of EuroQol 5-dimensions health status utility values in hereditary angioedema. Patient Prefer Adherence. 2016;10: 1699.

9 Fouche AS, Saunders EF, Craig T. Depression and anxiety in patients with hereditary angioedema. Ann Allergy Asthma Immunol. 2014;112(4):371-5.

10 Caballero T, Aygören-Pürsün E, Bygum A, Beusterien K, Hautamaki E, Sisic Z, et al. The humanistic burden of hereditary angioedema: results from the burden of illness study in Europe. Allergy Asthma Proc. 2014; 35(1):47-53.

11 Lumry WR, Castaldo AJ, Vernon MK, Blaustein MB, Wilson DA, Horn PT. The humanistic burden of hereditary angioedema: impact on health-related quality of life, productivity, and depression. Allergy Asthma Proc. 2010;31(5):407-14.

12 Tachdjian R, Johnson K, Casso D, Oliveria S, Devercelli G, Jain G. Real-world cohort study of adult and pediatric patients treated for hereditary angioedema in the United States. Allergy Asthma Proc. 2020.

13 Savarese L, Bova M, De Falco R, Guarino MD, De Luca Picione R, Petraroli A, et al. Emotional processes and stress in children affected by hereditary angioedema with $\mathrm{C} 1-$ inhibitor deficiency: a multicenter, prospective study. Orphanet J Rare Dis. 2018;13(1): 115.

14 Kuman Tunçel Ö, Gökmen NM, Demir E, Gülbahar O, Pırıldar Ş. The impact of hereditary angioedema on quality of life and family planning decisions. Int J Psychiatry Med. 2019;54(6):377-94.

15 Aabom A, Nguyen D, Fisker N, Bygum A Health-related quality of life in Danish children with hereditary angioedema. Allergy Asthma Proc. 2017;38(6):440.

16 Bygum A, Busse P, Caballero T, Maurer M. Disease severity, activity, impact, and control and how to assess them in patients with hereditary angioedema. Front Med. 2017;4: 212.
17 Engel-Yeger B, Farkas H, Kivity S, Veszeli N, Köhalmi KV, Kessel A. Health-related quality of life among children with hereditary angioedema. Pediatr Allergy Immunol. 2017;28(4):370-6.

18 Hahn J, Hoess A, Friedrich DT, Mayer B, Schauf L, Hoffmann TK, et al. Unnecessary abdominal interventions in patients with hereditary angioedema. J Dtsch Dermatol Ges. 2018;16(12):1443-9.

19 Lumry WR, Settipane RA. Hereditary angioedema: epidemiology and burden of disease. Allergy Asthma Proc. 2020.

20 Banerji A, Davis KH, Brown TM, Hollis K, Hunter SM, Long J, et al. Patient-reported burden of hereditary angioedema: findings from a US patient survey. Ann Allergy Asthma Immunol. 2020.

21 Maurer M, Aberer W, Agondi R, Al-Ahmad M, Al-Nesf MA, Ansotegui I, et al. Definition, aims, and implementation of GA2LEN/HAEi angioedema centers of reference and excellence. Allergy. 2020;75(8): 2115-23.

22 Weller K, Donoso T, Magerl M, AygörenPürsün E, Staubach P, Martinez-Saguer I, et al. Development of the angioedema control Test-A patient-reported outcome measure that assesses disease control in patients with recurrent angioedema. Allergy. 2020;75(5): 1165-77.

23 Weller K, Donoso T, Magerl M, AygörenPürsün E, Staubach P, Martinez-Saguer I, et al. Validation of the angioedema control test (AECT)-a patient reported outcome instrument for assessing angioedema control. J Allergy Clin Immunol Pract. 2020;8(6):20507.e4.

24 Kulthanan K, Chularojanamontri L, Rujitharanawong $\mathrm{C}$, Weerasubpong $\mathrm{P}$, Maurer $\mathrm{M}$, Weller K. Angioedema quality of life questionnaire (AE-QoL)-interpretability and sensitivity to change. Health Qual Life Outcomes. 2019;17(1):160.

25 Hinz A, Brähler E. Normative values for the hospital anxiety and depression scale (HADS) in the general German population. J Psychosom Res. 2011;71(2):74-8.

26 Spitzer RL, Kroenke K, Williams JB, Löwe B. $A$ brief measure for assessing generalized anxiety disorder: the GAD-7. Arch Intern Med. 2006;166(10):1092-7.

27 Zanichelli A, Longhurst HJ, Maurer $M$, Bouillet L, Aberer W, Fabien V, et al. Misdiagnosis trends in patients with hereditary angioedema from the real-world clinical setting. Ann Allergy Asthma Immunol. 2016; 117(4):394-8.

28 Zanichelli A, Magerl M, Longhurst $\mathrm{H}, \mathrm{Fa}-$ bien V, Maurer M. Hereditary angioedema with $\mathrm{C} 1$ inhibitor deficiency: delay in diagnosis in Europe. Allergy Asthma Clin Immunol. 2013;9(1):29.
29 Lunn ML, Santos CB, Craig TJ. Is there a need for clinical guidelines in the United States for the diagnosis of hereditary angioedema and the screening of family members of affected patients? Ann Allergy Asthma Immunol. 2010;104(3):211-4.

30 Magerl M, Gothe H, Krupka S, Lachmann A, Ohlmeier C. A Germany-wide survey study on the patient journey of patients with hereditary angioedema. Orphanet J Rare Dis. 2020;15(1):221-8.

31 Bygum A, Caballero T, Grumach AS, Longhurst HJ, Bouillet L, Aberer W, et al. Elderly versus younger patients with hereditary angioedema type I/II: patient characteristics and safety analysis from the icatibant outcome survey. Clin Transl Allergy. 2019;9(1): 37.

32 Bork K, Hardt J, Witzke G. Fatal laryngeal attacks and mortality in hereditary angioedema due to C1-INH deficiency. J Allergy Clin Immunol. 2012;130(3):692-7.

33 Longhurst $\mathrm{H}$, Bygum $\mathrm{A}$. The humanistic, societal, and pharmaco-economic burden of angioedema. Clin Rev Allergy Immunol. 2016;51(2):230.

34 Wang A, Fouche A, Craig TJ. Patients perception of self-administrated medication in the treatment of hereditary angioedema. Ann Allergy Asthma Immunol. 2015;115(2): 120.

35 Christiansen SC, Bygum A, Banerji A, Busse P, Li H, Lumry W, et al. Before and after, the impact of available on-demand treatment for HAE. Allergy Asthma Proc. 2015;36(2): $145-50$.

36 Lumry WR, Craig T, Zuraw B, Longhurst $\mathrm{H}$, Baker J, Li HH, et al. Health-related quality of life with subcutaneous C1-inhibitor for prevention of attacks of hereditary angioedema. J Allergy Clin Immunol Pract. 2018; 6(5):1733-41.e3.

37 Banerji A, Busse P, Christiansen SC, Li H, Lumry W, Davis-Lorton M, et al. Current state of hereditary angioedema management: a patient survey. Allergy Asthma Proc. 2015;36(3). 213-7.

38 Lumry WR, Weller K, Magerl M, Banerji A, Longhurst HJ, Riedl MA, et al. Impact of lanadelumab on health-related quality of life in patients with hereditary angioedema in the HELP study. Allergy. 2020.

39 Aygören-Pürsün E, Bygum A, Beusterien K, Hautamaki E, Sisic Z, Wait S, et al. Socioeconomic burden of hereditary angioedema: results from the hereditary angioedema burden of illness study in Europe. Orphanet Rare Dis. 2014;9:99.

40 Bygum A, Aygören-Pürsün E, Caballero T, Beusterien K, Gholizadeh S, Musingarimi P, et al. The hereditary angioedema burden of illness study in Europe (HAE-BOIS-Europe): background and methodology. BMC Dermatol. 2012;12(1):4 
41 Savarese L, Bova M, Maiello A, Petraroli A, Mormile I, Cancian M, et al. Psychological processes in the experience of hereditary angioedema in adult patients: an observational study. Orphanet J Rare Dis. 2021;16(1):23-7.

42 Viana AF, Maciel IS, Dornelles FN, Figueiredo CP, Siqueira JM, Campos MM, et al. Kinin B 1 receptors mediate depression-like behavior response in stressed mice treated with systemic E. coli lipopolysaccharide. J Neuroinflammation. 2010;7(1):98.

43 Freda MF, Savarese L, Bova M, Galante A, De Falco R, De Luca Picione R, et al. Stress and psychological factors in the variable clinical phenotype of hereditary angioedema in children: a pilot study. Pediatr Allergy Immunol Pulmonol. 2016;29(1):6-12.
44 Caballero T, Maurer M, Longhurst HJ, Aberer W, Bouillet L, Fabien V, et al. Triggers and prodromal symptoms of angioedema attacks in patients with hereditary angioedema. J Investig Allergol Clin Immunol. 2016; 26(6):383.

45 Aygören-Pürsün E, Magerl M, Maetzel A, Maurer M. Epidemiology of Bradykininmediated angioedema: a systematic investigation of epidemiological studies. Orphanet J Rare Dis. 2018;13(1):73.

46 Aygören-Pürsün E, Bygum A, Beusterien K, Hautamaki E, Sisic Z, Wait S, et al. Socioeconomic burden of hereditary angioedema: results from the hereditary angioedema burden of illness study in Europe. Orphanet J Rare Dis. 2014;9(1):99.
47 Psarros F, Koutsostathis N, Farmaki E, Speletas MG, Germenis AE. Hereditary angioedema in Greece: the first results of the Greek hereditary angioedema registry. Int Arch Allergy Immunol. 2014;164(4):326.

48 Hahn J, Trainotti S, Wigand M, Schuler P, Hoffmann T, Greve J. Prospective analysis in patients with HAE under prophylaxis with lanadelumab: a real-life experience. Drugs Dermatol. 2020;19(10):978-83.

49 Forjaz J, Ayala A, Caminoa M, Prior N, Pérez-Fernández E, Caballero T, et al. HAEAS, a specific disease activity scale for hereditary angioedema with $\mathrm{C} 1$-inhibitor deficiency. J Investig Allergol Clin Immunol. 2020. 